\title{
An Investigation of Attitudes toward Surveillance at Work and Its Correlates
}

\author{
Adrian Furnham1, Viren Swami2 \\ ${ }^{1}$ Department of Clinical, Educational, and Health Psychology, University College London, London, UK \\ ${ }^{2}$ Department of Psychology, Anglia Ruskin University, Cambridge, UK \\ Email: a.furnham@ucl.ac.uk
}

Received 27 June 2015; accepted 16 October 2015; published 19 October 2015

Copyright (C) 2015 by authors and Scientific Research Publishing Inc.

This work is licensed under the Creative Commons Attribution International License (CC BY).

http://creativecommons.org/licenses/by/4.0/

(c) $\underset{\mathrm{EY}}{\mathrm{i}}$ Open Access

\begin{abstract}
A large British sample completed measures of job autonomy and satisfaction as well as work discrimination and attitudes to authority measures along with a new surveillance at work measure. The new 16 item surveillance at work measure factored into two clear factors which reflected positive and negative attitudes to surveillance. Higher scores on Negative Aspects of Surveillance were significantly associated with lower job satisfaction, lower job autonomy, greater perceived discrimination at work, more negative attitudes to authority, and greater left-wing orientation while higher scores on Positive Aspects of Surveillance were significantly associated with greater job satisfaction and more positive attitudes toward authority.
\end{abstract}

\section{Keywords}

\section{Surveillance, Occupational, Attitudes toward Authority, Political Orientation, Job Satisfaction}

\section{Introduction}

The surveillance of employees in the workplace is a phenomenon that has always existed. However, in the past several decades, the advent of new technologies has meant that there is an increasing number of novel, cheap and reliable ways of monitoring employees. In most cases people know they are monitored (i.e. what information is being gathered) but not always when. It is often presented as possibly invasive but for "safety reasons”. However, there are other types of surveillance such as the monitoring of emails or internet use where people are unaware of when and why it occurs. This study concerns working people's general attitudes to surveillance at work.

Oz, Glass, \& Behling (1999) have listed eight methods of computer assisted electronic monitoring: video cameras (such as CCTV) computer sampling, e-mail interception, access codes, expert systems, transaction audits, phone taps and hidden microphones. Of these the most technologically advances are expert systems, which 
are more commonly referred to as EPM-“electronic performance monitoring”. The Office of Technological Assessment (Anon, 1987) described EPM as the "computerized collection, storage, analysis and reporting of information about employees' activities. In practice, EPM can be used to monitor a variety of mostly quantitative variables, such as the punctuality of employees, the amount of break time taken, the amount of idle time, the number of words written per minute, transactions completed, number of telephone calls made (time per call, revenue per call) just to name a few. In effect, this now means that there is a potential to monitor employees specific daily behaviours which has not been possible through traditional methods.

A clear and concise comparison between traditional "service observation" and newer "computer based monitoring" (Lund, 1992) describes the former as "discreet [in occurrence], [performed by a] supervisor, [monitoring] usually qualitative measures such as courtesy, tone, attitude and accuracy of information" and the latter as "continuous [in occurrence], [performed by] computer hardware and peripherals, [monitoring] usually quantitative measure of production (keystrokes, claims/hour, etc.)”. This was based on the OTA report 1987.

As these newer methods of surveillance offer continuous monitoring over an employees' time at work, this has unsurprisingly ignited much debate over whether it is morally right or even organizationally wise to implement such control. So far, there have been numerous studies conducted looking into the possible effects of EPM, by comparing EPM and non-EPM scenarios and measuring factors such as stress, productivity, job satisfaction, turnover etc. These have mainly used cross-sectional studies, observational studies and a few laboratory studies. However, less research has been conducted into looking at people's attitudes towards surveillance, and what factors and traits may correlate with them.

While many studies looked at the correlation between monitoring and stress, Kolb \& Aiello (1996) looked specifically at examining how monitoring affected the stress levels of participants split into two groups, depending on whether they were assessed to have an internal or external locus of control, based on a questionnaire. They were then assigned randomly to either a monitored or non-monitored group and made to complete a simple data entry or vowel/consonant task. Afterwards they answered questions aimed at measuring how stressed the test made them feel. Interestingly, neither the monitored nor non-monitored group felt an increase in stress, going against previous research showing that monitoring tends to increase stress (Amick \& Smith 1992; Rogers et al., 1990). However, it was found that in those participants with an external locus of control, monitoring decreased their levels of stress, while the opposite effect was demonstrated in those with an internal locus of control (Kolb \& Aiello, 1996).

These results differ to a previous study (Aiello \& Svec, 1993) in which a complex anagram solving task was used instead of simple tasks, and it was found that those with an internal locus of control demonstrated greater anxiety when not monitored, while those with an external locus of control demonstrated greater anxiety when monitored. In light of these two seemingly conflicting results from the laboratory studies, one could explain that the phenomenon is dependent also on the complexity of the task.

A large scale questionnaire-based cross-sectional study looking into people's attitudes towards electronic monitoring was done by Oz et al. (1999). The responses of 823 part time students who were in full time employment were analysed, mainly looking for differences between the attitudes of supervisor and their subordinates, but also for any gender differences. Predictably, it found that supervisors were more likely to support the idea of electronic monitoring, while also suggesting that it would be a good tool in reducing theft. Meanwhile subordinates (non-supervisors) expressed greater agreement with the idea that electronic monitoring would have a negative impact and create tensions in the workplace, as well as agreeing that employees should be made aware of when monitoring is taking place. In terms of gender differences, it was found that women were more likely than men to think that monitoring would reduce theft (Oz et al., 1999).

In a more recent study Samaranayake \& Gamage (2011) looked at how electronic monitoring affected employees' satisfaction. They gathered data from 380 employees of a computer software company, using a questionnaire containing 75 questions, each answered on a five point Likert scale, in order to assess their job satisfaction as well as the employees' perception of task satisfaction, relevance to work, invasion of privacy, level of infringement, rationale of employer and judgment of effectiveness. It was found that job satisfaction was positively correlated with those workers who had a positive opinion of electronic monitoring. This supports the idea that monitoring is fair, unbiased and provides a fuller image of the employee. However, it did also show that the greater the perception of invasion of privacy, the lower the job satisfaction was, and this was also true in those that felt that monitoring made their work more complex. Interestingly, by looking at subgroups it was found that the effect that monitoring had on job satisfaction was much weaker in those employees with a higher profes- 
sional experience (Samaranayake \& Gamage, 2011).

From these we can gather that there is still much to be learnt about what correlates with people's attitudes towards surveillance in the workplace, especially considering that some studies have produced contradictory results, or results which are difficult to explain. This leaves ample room for more wide-scale investigations into attitudes and possible factors that may correlate with them. The first task is to devise a good measure of attitudes to survellience. This study set out to devise such a measure and look at various correlates like participants' attitudes to job satisfaction, autonomy and discrimination as well as their attitudes to authority. Further we examined sex, age and political orientation correlates of surveillance attitudes. Following previous studies we predicted that those with general negative attitudes to surveillance would express lower job satisfaction, autonomy and discrimination as well as being, in general, more against authority. We also expected older people, females, and those with left wing politics to be more positive to surveillance compared to younger people, males and those with right wing politics.

\section{Method}

\subsection{Participants}

Participants of this study were 283 women and 342 men recruited from the community in London, England (age range 18 - 70 years, $M=31.83, \mathrm{SD}=11.50$ ). Of this sample, 400 individuals were in full-time employment and 225 individuals were in part-time employment in a wide variety of jobs. The majority of the sample had permanent contracts (63.5\%), while $27.8 \%$ had temporary (casual) contracts, and $8.6 \%$ had fixed-term contracts. In terms of ethnicity, $65.0 \%$ self-reported as being of British White descent, $23.0 \%$ of Asian descent, 3.8\% of African Caribbean descent, and the remainder of other ancestry. Of the total sample, $7.8 \%$ had completed minimum secondary schooling as their highest qualification, $22.2 \%$ had a college diploma, $31.6 \%$ had an undergraduate degree, $32.5 \%$ had a postgraduate degree, and the remainder had some other educational qualification. They were clearly more educated than the population as a whole. Most participants were not members of a trade union (85.8\%), whereas $14.2 \%$ were.

\subsection{Materials}

Surveillance at work. To measure attitudes toward surveillance at work, we purpose-designed a novel 16-item scale using standard scale-development procedures (Spector, 1992). The first and final authors initially reviewed the available literature on surveillance at work and, based on this review, generated items independently. We found that attitudes were most salient with respect to the consequences of surveillance rather than the particular type of surveillance/monitoring or the said purpose of it. These items were then discussed in a group session until consensus was reached and redundant items omitted. The resulting items were then pilot-tested on 30 British employees who were not re-sampled in the main study. Interviews were conducted with the pilot-test participants to assess the appropriateness of the items for the British employment context and for clarity. This process led to the final version of the Surveillance at Work Scale (SWS), which consisted of the 16 items presented in Table 1. In the main study, the items on this scale were rated on a 7-point Likert-type scale $(1=$ Strongly disagree, $7=$ Strongly agree). The factor structure and reliability of this scale is explored in the Results.

Job satisfaction. Job satisfaction was measured using a standardised, 7-item instrument (Smith, Johal, Wadsworth, Davey Smith, \& Peters, 2000). Items on this scale were rated on a 4-point Likert-type scale (1 = Very dissatisfied, 7 = Very satisfied) and an overall score was computed as the mean of all 7 items. Higher scores on this scale indicate greater satisfaction with multiple aspects of an individual's occupation, such as the salary, physical work conditions, and job prospects. Previous work with the scale has shown that it is reliable and has a good pattern of convergent validity (e.g., Bedi, Furnham, \& Swami, 2012; Smith et al., 2000). In the present study, Cronbach's alpha for this scale was 83.

Job autonomy. To measure autonomy at work, we used a standardised, 8-item scale (Smith et al., 2000) in which items were rated on a 4-point, Likert-type scale ( 1 = Often, $4=$ Never/Almost never $)$. An overall score of job autonomy was computed as the mean of all 8 items, with higher scores indicating lower job autonomy on multiple aspects of an occupation, including flexibility of working time and job speed. A previous study has reported that this scale has good reliability and patterns of validity (Smith et al., 2000). In the present study, Cronbach’s alpha for this scale was .74. 
Table 1. Items in the novel surveillance at work scale and factor loadings following exploratory factor analysis (values in bold indicate that an item loads onto a factor).

\begin{tabular}{|c|c|c|}
\hline & Factor 1 & Factor 2 \\
\hline (1) Surveillance demoralises me and my colleagues. & .79 & -.11 \\
\hline (2) Surveillance reduces creativity at work. & .77 & -.03 \\
\hline (3) Surveillance at work makes employees feel weak and powerless compared to the employer. & .76 & .03 \\
\hline (4) The use of surveillance at work implies that employers do not trust their emploiyees. & .76 & -.14 \\
\hline (5) Surveillance at work erodes trust between employers and employees. & .75 & .22 \\
\hline (6) Surveillance at work increases my levels of stress. & .74 & -.10 \\
\hline (7) Surveillance alienates employees because it makes them more likely to self-police each other. & .66 & .01 \\
\hline (8) Surveillance at work represents a violation of my right to privacy. & .58 & -.05 \\
\hline $\begin{array}{l}\text { (9) There is nothing wrong with surveillance at work because if a person isn't doing something } \\
\text { wrong, then they shouldn't have anything to fear. }\end{array}$ & .07 & .74 \\
\hline (10) Knowing that surveillance systems exist at work gives me a sense of security. & .06 & .72 \\
\hline (11) Surveillance helps to reduce sexual harassment in the workplace. & -.21 & .64 \\
\hline (12) Surveillance helps to reduce bullying in the workplace. & .14 & .62 \\
\hline $\begin{array}{l}\text { (13) The use of surveillance systems increases work safety by allowing supervisors to act } \\
\text { before a crime is committed. }\end{array}$ & -.10 & .61 \\
\hline $\begin{array}{l}\text { (14) Surveillance systems at work are useful because they make employees less willing } \\
\text { to commit a crime if they know they are being watched. }\end{array}$ & -.13 & .60 \\
\hline (15) Surveillance at work is acceptable if it concerns the security of the workplace. & -.01 & .54 \\
\hline (16) Surveillance at work helps to improve employee productivity. & -.21 & .45 \\
\hline
\end{tabular}

Note. Items were presented in a random order in the survey.

Workplace discrimination. To measure workplace discrimination, we used an adapted version of the Everyday Discrimination Scale (EDS; Williams, Yu, Jackson, \& Anderson, 1997). In its original version, the 9-item EDS taps perceived discrimination that is chronic, minor, and recurring. The scale is also generic and has been used in studies of stress-related well-being in a range of settings (for a review, see Williams \& Neighbors, 2001). In the present study, we altered the stem question so that it referred to experiences in the workplace specifically. In addition, we also dropped one item that referred specifically to service in restaurants and stores. The adapted, 8-item measure of workplace discrimination was rated on a 6-point, Likert-type scale $(1=$ Never, $6=$ Almost always). An overall score was computed as the mean of all 8 items, with higher scores reflecting greater perceived discrimination in the workplace. Cronbach's alpha for our adapted EDS was .87.

Attitudes towards authority. We used an adapted version of the Attitudes Toward Authority Scale (Reicher \& Emler, 1985). The original scale has been adapted to tap attitudes relating to institutional authority, bias by those in authority, and the absolute priority of rules, while removing items related to the fairness of school rules (Swami, Chamorro-Premuzic, \& Furnham, 2010). The adapted measure contains 10 items that are rated on a 5-point Likert-type scale ( 1 = Strongly disagree, 5 = Strongly agree) and an overall score is computed as the mean of all ten items. Higher scores on this scale reflect more negative attitudes towards authority. Previous studies have shown that this adapted version of the Attitudes Toward Authority Scale has good internal consistency (Swami et al., 2010, 2011) and a good pattern of convergent validity. In the present study, Cronbach's alpha for this scale was .79.

Occupational data. Participants were asked whether they were in full-time or part-time employment, and whether their contract was permanent, temporary (casual), or fixed-term. Finally, participants were also asked whether they are members of a trade union ( $1=$ Yes, 2 = No, 3 = Not sure).

Demographics. Participants were asked to provide their sex, age, ethnicity, and highest educational qualifica- 
tion. They were also asked to rate their political orientation on a 7 -point scale $(1=$ Strongly right-wing, $7=$ Strongly left-wing).

\subsection{Procedures}

Ethical approval for this study was obtained from the relevant university ethics committee. Participant recruitment was conducted using a snowball-sampling technique initiated by three research assistants. Specifically, participants who met sampling criteria of being in employment in Britain were invited to take part in a study on workplace issues and these participants then recruited further participants from their own social networks. Once participation had been agreed, participants provided informed consent and completed a paper-and-pencil survey in which the order of presentation of scales was semi-randomised (occupational and demographic questions always appeared first). All participants took part on a voluntary basis and were not remunerated for participation. Once the survey had been completed and returned, participants were provided with a debrief sheet that included contact details of the final author.

\section{Results}

\subsection{Surveillance at Work}

In order to examine the factor structure of the SWS, we computed principal-axis exploratory factor analysis (EFA) for the total sample using varimax rotation (Pedhazur \& Schmelkin, 1991). The number of factors to be extracted was determined by factor eigenvalues above 1.0 (the EGV1 criterion) and based on the scree-plot criterion (Cattell, 1966). However, these techniques can lead to factor over-retention (Patil, McPherson, \& Friesner, 2010), so parallel analysis was also conducted. This technique generates eigenvalues from random datasets that match the actual dataset in terms of the number of participants and variables, and is considered a more accurate technique for determining the number of factors to retain from EFA (Hayton, Allen, \& Scarpello, 2004).

Barlett's test of sphericity, $\chi^{2}(120)=3224.95, p<.001$, and the KMO measure of sampling adequacy, KMO $=.88$, showed that the SWS items had adequate common variance for factor analysis. The EGV1 criterion and examination of the scree-plot suggested it was possible to extract three factors after four iterations. However, parallel analysis showed that the first two eigenvalues for the random data (1.96 and 1.82) were smaller than their real data counterparts (4.50 and 2.81), whereas the third eigenvalue for the random data (1.47) was larger than the third eigenvalue for the real data (1.37), suggesting that two factors should be retained (see Table 1 for item loadings).

The first factor included items that reflected negative aspects of surveillance at work and explained $28.1 \%$ of the variance. The second factor appeared to reflect more positive aspects of surveillance at work, explaining $17.6 \%$ of the variance. It is quite likely that this factor structure was affected by the directionality of items, with positively- and negatively-worded items loading differentially (Schmitt \& Stults, 1985). Even so, the two factors were only weakly correlated $(\mathrm{r}=-.15, p<.001)$, suggesting that they may be measuring different constructs. We, therefore, computed overall scores for both factors by taking the mean of all items associated with each factor. Both Negative Aspects $(\alpha=.87)$ and Positive Aspects of Surveillance $(\alpha=.81)$ had good internal consistency.

A paired-samples t-test indicated that participants gave significantly higher ratings to Positive Aspects $(\mathrm{M}=$ $4.17, \mathrm{SD}=1.06)$ than they did Negative Aspects $(\mathrm{M}=3.47, \mathrm{SD}=1.18), \mathrm{t}(618)=10.13, p<.001, \mathrm{~d}=0.81$. Independent-samples t-tests indicated that there were no sex differences on ratings of Negative Aspects, $\mathrm{t}(617)=$ $0.85, p=.396, \mathrm{~d}=0.07$, or Positive Aspects, $\mathrm{t}(617)=0.87, p=.383, \mathrm{~d}=0.07$. There were also no significant differences depending on whether participants were in full-time or part-time employment for ratings of Negative Aspects, $\mathrm{t}(617)=0.99, p=.321, \mathrm{~d}=0.08$, or positive aspects, $\mathrm{t}(617)=0.62, p=.539, \mathrm{~d}=0.05$. Univariate analyses of variance (ANOVAs) indicated that there were no significant differences on ratings of both Negative and Positive Aspects as a function of contract type or trade union membership ( $<<3.19, p>.073)$.

\subsection{Inter-Scale Relationships}

To examine correlates of attitudes toward surveillance at work, we intially computed bivariate correlations between factors scores for Negative and Positive aspects, respectively, and all remaining parametric variables (job 
satisfaction, job autonomy, workplace discrimination, attitudes toward authority, participant age, and political orientation). As can be seen in Table 2, higher scores on Negative Aspects of Surveillance were significantly associated with lower job satisfaction, lower job autonomy, greater perceived discrimination at work, more negative attitudes to authority, and greater left-wing orientation, confirming many hypotheses. On the other hand, higher scores on Positive Aspects of Surveillance were significantly associated with greater job satisfaction and more positive attitudes toward authority. It should be noted, however, that significant correlations tended to be weak (r's $<.26)$.

To further examine these associations, we conducted multiple linear regressions (forced-entry method) with Negative and Positive Aspects, respectively, as criterion variables and all remaining factors as predictor variables. The regression with Negative Aspects was significant, $\mathrm{F}(6,614)=12.73, p<.001$, Adj. $\mathrm{R}^{2}=.10$. Of the variables entered into the model, Negative Aspects of Surveillance was significantly predicted by more negative attitudes toward authority $(\mathrm{B}=.46, \mathrm{SE}=.12, \beta=.16, \mathrm{t}=4.01, p<.001)$, more left-wing orientation $(\mathrm{B}=.14$, $\mathrm{SE}$ $=.04, \beta=.15, \mathrm{t}=3.79, p<.001)$, lower job satisfaction $(\mathrm{B}=-.28, \mathrm{SE}=.08, \beta=-.14, \mathrm{t}=-3.57, p<.001)$, and greater perceived discrimination at work $(\mathrm{B}=.23, \mathrm{SE}=.07, \beta=.15, \mathrm{t}=3.52, p<.001)$. The regression with Positive Aspects was likewise significant, $\mathrm{F}(6,614)=10.26, p<.001$, Adj. $\mathrm{R}^{2}=.08$, but the only significant predictors were more positive attitudes to authority $(\mathrm{B}=.61, \mathrm{SE}=.11, \beta=.23, \mathrm{t}=5.74, p<.001)$ and greater job satisfaction $(\mathrm{B}=.31, \mathrm{SE}=.07, \beta=.17, \mathrm{t}=4.32, p<.001)$.

\section{Discussion}

As it increases in the workplace, it would seem likely that research into attitudes toward as well as responses to surveillance will increase. This study set above developing a short, robust and valid measure of these attitudes which can be seen in Table 1. The results showed that the measure has two clear factors, the one negative and the other positive which were only modestly negatively correlated $(r=-.15)$ as they were essentially looking at rather different aspects of surveillance. This point is emphasized in the correlational results which showed that the two factors correlated quite differently with the various other measures used.

Those who were more negative about work place surveillance were less job satisfied, experienced less autonomy at work, perceived more discrimination, had a negative attitude to authority and tended to more left wing. To a large extent, this may be seen as the profile of an alienated worker, unhappy at work, disgruntled and dissatisfied with all aspects of their work situation. To this kind of worker, particularly if they had reasonable autonomy at work, which may in part mean they were relatively unsupervised, the very idea of any sort of surveillance is abhorrant. One important question is how a person comes to be so negative at work: to what extent this is due to a pessimistic personality (unstable introversion) or the extent is due to poor supervision and corrupt or incompetent organisational practices.

The positive attitudes factor correlated with only two other variables: job satisfaction and attitudes to authority. Those who were more jobs satisfied and tended to trust authority more were more positive about surveillance.

Table 2. Inter-scale correlations between attitudes toward surveillance at work and other variables measured in the present study.

\begin{tabular}{|c|c|c|c|c|c|c|c|}
\hline & $(2)$ & (3) & (4) & (5) & (6) & (7) & (8) \\
\hline (1) Negative WS & $-.15^{* *}$ & $-.16^{* *}$ & $.10^{*}$ & $.21^{* *}$ & $.17^{* *}$ & -.05 & $.19^{* *}$ \\
\hline (2) Positive WS & & $.18^{* *}$ & .07 & .04 & $-.25^{* *}$ & -.03 & .03 \\
\hline (3) Job Satisfaction & & & -.07 & $-.21^{* *}$ & $.09^{*}$ & $.16^{* *}$ & -.03 \\
\hline (4) Job Autonomy & & & & $.30^{* *}$ & .08 & $-.11^{*}$ & .05 \\
\hline (5) Job Discrimination & & & & & .07 & $-.14^{* *}$ & $.13^{*}$ \\
\hline (6) Attitudes toAuthority & & & & & & .02 & $.12^{*}$ \\
\hline (7) Age & & & & & & & $-.10^{*}$ \\
\hline (8) Political Orientation & & & & & & & \\
\hline
\end{tabular}

Note. $N=625 .{ }^{*} p<.05,{ }^{* *} p<.001$. 
All this makes sense but begs the question as to whether indeed there are essentially positive and negative people: the former being sanguine, optimistic and trusting and therefore likely to be more accepting of management policies and procedures in general; negative people seem choleric and melancholic unhappy at work, distrustful and therefore suspicious of any and all surveillance techniques. This thesis remains to be tested.

This study must represent the first in a relatively unexplored area. There seem to be very few measures of attitudes to surveillance. In this study we have a short, two dimensional measure which warrants further development. We expected that it would have a more complex structure reflecting different types of, and reasons for surveillance. Also in this study we measured four other attitude factors (job autonomy, discrimination, satisfaction and attitudes to authority) which we suspected would be correlated with surveillance attitudes. Indeed they were but the correlations were modest and the two regressions accounted for only $8 \%$ and $10 \%$ of the variance. The question remains as to what other intra- or inter-individual difference factors more strongly relate to attitudes to surveillance. In this study we did not enquire about the participants' personal experience of workplace which may have shaped their attitudes. More importantly we did not gather information on their particular occupation, their perception of working conditions or managerial behaviours which may be expected to influence surveillance attitudes.

Future studies may examine the effects of the introduction of surveillance technology on the attitudes of those who are being monitored. How the surveillance technology is introduced and with what managerial explanations no doubt influences attitudes to it before and after its introduction. Further attitudes of customers to surveillance (where appropriate) are also worthy of investigation.

\section{References}

Aiello, J. R., \& Svec, C. M. (1993). Computer Monitoring and Work Performance: Extending the Social Facilitation Framework to Electronic Presence. Journal of Applied Social Psychology, 23, 537-548.

http://dx.doi.org/10.1111/j.1559-1816.1993.tb01102.x

Amick, B. C., \& Smith, M. J. (1992). Stress, Computer-Based Work Monitoring and Measurement Systems: A Conceptual Overview. Applied Ergonomics, 23, 6-16. http://dx.doi.org/10.1016/0003-6870(92)90005-G

Anon (1987). The Electronic Supervisor: New Technology, New Tensions (Office of Technology Assessment, Congress of the United States; OTA-CIT-333). Washington DC: Government Printing Office.

Bedi, R., Furnham, A., \& Swami, V. (2012). Predictors of Job Satisfaction among General Practitioners of South Asian Descent in Britain. In R. Bedi, E. Davidson, \& J. J. Liu (Eds.), Indian Health Professionals around the World: A Common Agenda (pp. 121-127). New Delhi: Global Association of Physicians of Indian Origin (GAPIO).

Cattell, R. B. (1966). The Scree Plot Test for the Number of Factors. Multivariate Behavioral Research, 1, 140-161. http://dx.doi.org/10.1207/s15327906mbr0102_10

Hayton, J. C., Allen, D. G., \& Scarpello, V. (2004). Factor Retention Decisions in Exploratory Factor Analysis: A Tutorial on Parallel Analysis. Organization Research Methods, 7, 191-205. http://dx.doi.org/10.1177/1094428104263675

Kolb, K. J., \& Aiello, J. R. (1996). The Effects of Electronic Performance Monitoring on Stress: Locus of Control as a Moderator Variable. Computers in Human Behavior, 12, 407-423. http://dx.doi.org/10.1016/0747-5632(96)00016-7

Lund, J. (1992). Electronic Performance Monitoring: A Review of Research Issues. USA: School of Workers, University of Wisconsin-Extension. http://dx.doi.org/10.1016/0003-6870(92)90011-j

Oz, E., Glass, R., \& Behling, R. (1999). Electronic Workplace Monitoring: What Employees Think. International Journal of Management Science, 27,167-177. http://dx.doi.org/10.1016/s0305-0483(98)00037-1

Patil, V. H., McPherson, M. Q., \& Friesner, D. (2010). The Use of Exploratory Factor Analysis in Public Health: A Note on Parallel Analysis as a Factor Retention Criterion. American Journal of Health Promotion, 24, 178-181. http://dx.doi.org/10.4278/ajhp.08033131

Pedhazur, E. J., \& Schmelkin, L. P. (1991). Measurement, Design, and Analysis: An Integrated Approach. Hillsdale, NJ: Lawrence Erlbaum Associates.

Reicher, S., \& Emler, N. (1985). Delinquent Behaviour and Attitudes to Formal Authority. British Journal of Social Psychology, 24, 161-168. http://dx.doi.org/10.1111/j.2044-8309.1985.tb00677.x

Rogers, K. J. S., Smith, M. J., \& Sainfort, P. C. (1990). Electronic Performance Monitoring, Job Design, and Psychological Stress. Proceedings of the Human Factors Society, 34, 854-858. http://dx.doi.org/10.1177/154193129003401206

Samaranayake, V., \& Gamage, C. (2011). Employee Perception towards Electronic Monitoring at Work Place and Its Impact on Job Satisfaction of Software Professionals in Sri Lanka. Telematics and Informatics, 29, 233-244.

http://dx.doi.org/10.1016/j.tele.2011.08.003 
Smith, A., Johal, S., Wadsworth, E., Davey Smith, G., \& Peters, T. (2000). The Scale of Occupational Stress: The Bristol Stress and Health at Work Study. Contract Research Report 265/2000, London: HSE Books.

Spector, P. E. (1992). Summated Rating Scale Construction: An Introduction. Newbury Park, CA: Sage. http://dx.doi.org/10.4135/9781412986038

Swami, V., Chamorro-Premuzic, T., \& Furnham, A. (2010). Unanswered Questions: A Preliminary Investigation of Personality and Individual Difference Predictors of 9/11 Conspiracist Beliefs. Applied Cognitive Psychology, 24, 749-761. http://dx.doi.org/10.1002/acp.1583

Swami, V., Coles, R., Stieger, S., Pietschnig, J., Furnham, A., Rehim, S., \& Voracek, M. (2011). Conspiracist Ideation in Britain and Austria: Evidence of a Monological Belief System and Associations between Individual Psychological Differences and Real-World and Fictitious Conspiracy Theories. British Journal of Psychology, 102, 443-463. http://dx.doi.org/10.1111/j.2044-8295.2010.02004.x

Williams, D. R., \& Neighbors, H. (2001). Racism, Discrimination, and Hypertension: Evidence and Needed Research. Ethnicity and Disease, 11, 800-816.

Williams, D. R., Yu, Y., Jackson, J., \& Anderson, N. (1997). Racial Differences in Physical and Mental Health: Socioeconomic Status, Stress, and Discrimination. Journal of Health Psychology, 2, 335-351.

http://dx.doi.org/10.1177/135910539700200305 